\title{
The Immunity Regulator BAK1 Contributes to Resistance Against Diverse RNA Viruses
}

\author{
Camilla Julie Kørner, ${ }^{1}$ Dominik Klauser, ${ }^{1}$ Annette Niehl, ${ }^{1}$ Ana Domínguez-Ferreras, ${ }^{1}$ \\ Delphine Chinchilla, ${ }^{1}$ Thomas Boller, ${ }^{1}$ Manfred Heinlein,, ${ }^{1,2}$ and Dagmar R. Hann ${ }^{1}$
}

'Zurich-Basel Plant Science Center, Department of Environmental Sciences, University of Basel, Hebelstrasse 1, 4056 Basel, Switzerland; ${ }^{2}$ Institut de Biologie Moléculaire des Plantes du CNRS, 12 Rue du Général Zimmer, 67000 Strasbourg, France

Submitted 8 May 2013. Accepted 22 July 2013.

\begin{abstract}
The plant's innate immune system detects potential biotic threats through recognition of microbe-associated molecular patterns (MAMPs) or danger-associated molecular patterns (DAMPs) by pattern recognition receptors (PRR). A central regulator of pattern-triggered immunity (PTI) is the BRI1-associated kinase 1 (BAK1), which undergoes complex formation with PRR upon ligand binding. Although viral patterns inducing PTI are well known from animal systems, nothing similar has been reported for plants. Rather, antiviral defense in plants is thought to be mediated by post-transcriptional gene silencing of viral RNA or through effector-triggered immunity, i.e., recognition of virus-specific effectors by resistance proteins. Nevertheless, infection by compatible viruses can also lead to the induction of defense gene expression, indicating that plants may also recognize viruses through PTI. Here, we show that PTI, or at least the presence of the regulator BAK1, is important for antiviral defense of Arabidopsis plants. Arabidopsis bak1 mutants show increased susceptibility to three different RNA viruses during compatible interactions. Furthermore, crude viral extracts but not purified virions induce several PTI marker responses in a BAK1-dependent manner. Overall, we conclude that BAK1-dependent PTI contributes to antiviral resistance in plants.
\end{abstract}

Both plants and animals perceive microbe-associated molecular patterns (MAMPs) as a first line of defense against potential microbial pathogens (Boller and Felix 2009; Janeway and Medzhitov 2002; Zipfel and Felix 2005). Such MAMPs are broadly conserved molecular microbial structures essential for the microbial lifestyle and are absent from the host. Upon MAMP perception by pattern recognition receptors (PRR), a signaling cascade is initiated that ultimately leads to patterntriggered immunity (PTI) (Boller and Felix 2009; Janeway and Medzhitov 2002).

PTI is well studied in animals and is active against a wide range of different pathogens, including viruses. The best-characterized PRR in animals are Toll-like receptors (TLR) that recognize a wide range of MAMPs, including viral RNA and

C. J. Kørner and D. Klauser contributed equally.

Corresponding authors: D. R. Hann; E-mail: dagmar.hann@unibas.ch and M. Heinlein; E-mail: manfred.heinlein@unibas.ch or manfred.heinlein@ibmp-cnrs.unistra.fr

* The $\boldsymbol{e}$-Xtra logo stands for "electronic extra" and indicates that four supplementary figures are published online.

(C) 2013 The American Phytopathological Society
DNA (Song and Lee 2012). In order to permit efficient detection of extracellular and intracellular microbes, animal TLR are either localized to the plasma membrane or associated with the endomembrane system (Jensen and Thomsen 2012). As viruses are obligate intracellular pathogens, they are predominately recognized by intracellular receptors such as TLR3, TLR7, and TLR8 for viral RNA and TLR9 for viral DNA (Jensen and Thomsen 2012; Rathinam and Fitzgerald 2011).

In plants, no similar mechanisms have been described thus far. Antiviral defense strategies in plants thought to be mediated by recognition and subsequent degradation of viral genomic RNA or replication intermediates by the host post-transcriptional gene-silencing machinery leading to the generation of viral small interfering RNAs (vsiRNA) (Ruiz-Ferrer and Voinnet 2009). The production of vsiRNAs leads to sequence-specific degradation or translational inhibition of viral target RNAs (Ding 2010). However, whether or not virus-specific molecules are directly recognized by innate immune receptors in plants, as in animal systems, is still unknown.

In plants, the molecular mechanisms underlying PTI share a number of features known from MAMP perception systems in animals (Boller and Felix 2009). Today, several MAMPs from fungi, oomycetes, and bacteria, as well as a number of plant PRR involved in their perception are known. However, there are no equivalent MAMPs derived from viruses. All currently known PRR of plants appear to be plasma membrane proteins with an extracellular receptor domain and either an intracellular kinase domain (receptor-like kinases $[\mathrm{RLK}]$ ) or without a structured intracellular domain (receptor-like proteins [RLP]). Interestingly, a number of these RLK and RLP have been shown or are believed to interact with the leucine-rich repeat RLK BAK1 (BRI1-associated kinase 1) upon ligand binding (Chinchilla et al. 2007; Heese et al. 2007; Schulze et al. 2010). This interaction likely leads to cross phosphorylation between the two kinases and subsequent activation of downstream signaling (Schulze et al. 2010; Schwessinger et al. 2011). As BAK1 interacts with several PRR, it is regarded to be a general regulator of plant immunity (Chinchilla et al. 2007, 2009; Heese et al. 2007).

Plants also have surveillance systems to monitor cell integrity in a mechanistically similar manner to PTI. Wounding of Arabidopsis plants, for example, is believed to induce the production of small peptides (AtPEP) that are relatively poorly conserved among higher plants and are derived from longer peptides (ProPEP) (Huffaker and Ryan 2007; Krol et al. 2010; Wasternack et al. 2006; Yamaguchi and Huffaker 2011). Similarly to many MAMPs, AtPEP are perceived by two PRR, namely, PEP-receptor 1 (PEPR1) and PEPR2 (Krol et al. 2010). Interestingly, PEPR1 and PEPR2 also interact with BAK1 upon 
AtPEP recognition, which leads to the induction of a stereotypical defense response reminiscent of PTI (Boller and Felix 2009; Krol et al. 2010). Thus, BAK1 is a central player in different aspects of immunity, including classical PTI as well as danger-associated molecular pattern (DAMP) signaling and, thus, constitutes an ideal molecular tool for the identification of novel components of immunity.

Given the similarities between plant and animal innate immune systems, we hypothesized that plant viruses also induce PTI by yet-unknown mechanisms. This hypothesis is supported by the induction of gene expression typically associated with PTI and salicylic acid (SA) signaling during compatible viral infections (Carr et al. 2010; Love et al. 2005; Hanssen et al. 2011; Whitham et al. 2003). To test this hypothesis, we infected a range of PTI signaling mutants with three different RNA viruses and found that plants mutated for the common regulator of PTI, i.e., BAK1, exhibited increased susceptibility to virus infection. This suggested that viral elicitors or DAMPs produced in response to the virus were recognized in a BAK1-dependent manner and that specific recognition of these molecular patterns contributed to resistance against these viruses. Consistently, we found that extracts of infected plants induced PTI responses in Arabidopsis, such as mitogen-activated protein kinase (MAPK) activation, increased production of the plant hormone ethylene, or root-growth inhibition in a BAK1-dependent manner, when applied to healthy plants. In conclusion, we show that BAK1 is involved in antiviral defenses in plants, and we

A

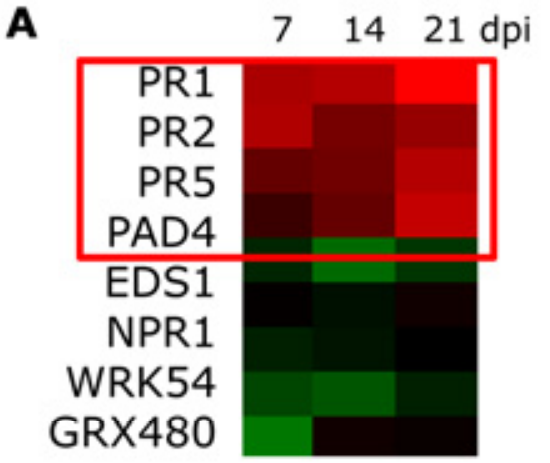

C

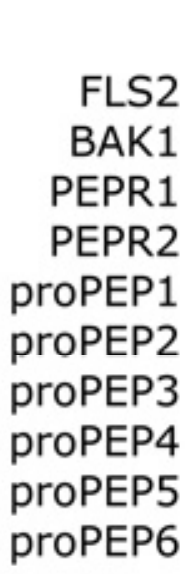

$21 \mathrm{dpi}$

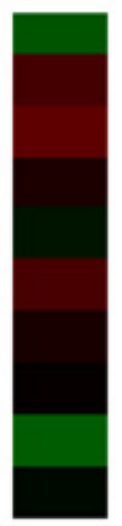

provide evidence that virus-encoded MAMPs or virus-induced DAMPs elicit classical PTI responses.

\section{RESULTS}

Analysis of publicly available microarray data (Carr et al. 2010; Hanssen et al. 2011; Love et al. 2005; Whitham et al. 2003)) and a previously published microarray analysis of cDNA derived from tissue of Arabidopsis plants infected with the tobamovirus Oilseed rape mosaic virus (ORMV) (Hu et al. 2011) revealed that genes related to innate immunity exhibited modulated expression during compatible virus infections and that these gene-expression changes increased over time (Fig. 1; Supplementary Fig. S1). Interestingly, PEPRI and ProPEP2 were also induced. Hence, we speculated that compatible virus infection could also interfere with DAMP signaling. To test whether DAMP-signaling was indeed induced upon virus infection, we infected Arabidopsis wild-type (WT) Col-0 plants with purified virions of three different RNA viruses, namely, the tobamovirus Tobacco mosaic virus (TMV) strains U1 and ORMV and the tombusvirus Turnip crinkle virus (TCV). TCV and ORMV both cause strong symptoms in Arabidopsis plants, while TMV causes only very mild symptoms in Arabidopsis (Dardick et al. 2000). The transcripts of the precursor proteins AtProPEP2 and AtProPEP3, which are known to be induced by wounding, biotic stress, and MAMP signaling (Huffaker and Ryan 2007), were strongly upregulated by all three RNA

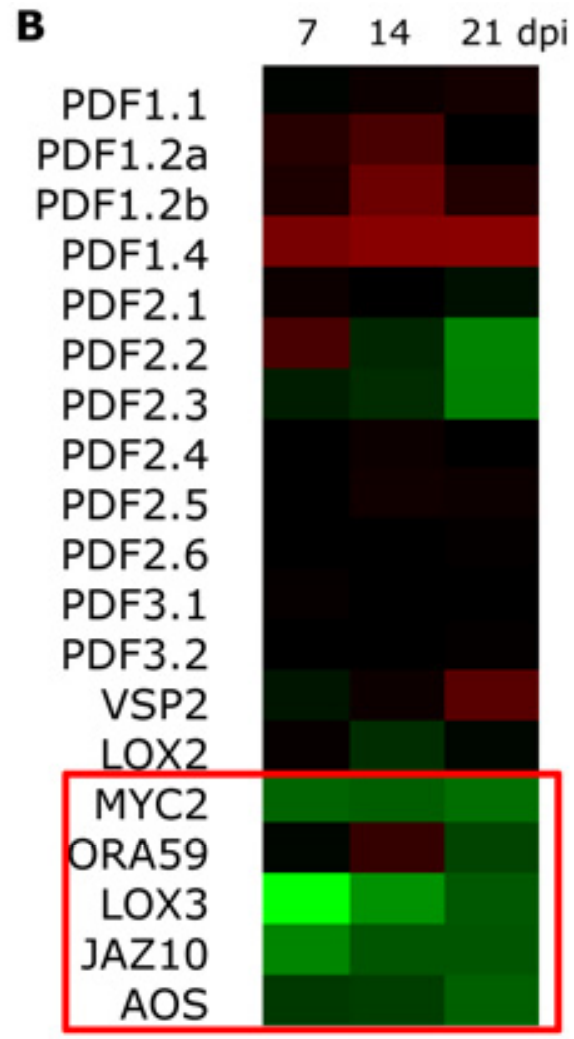

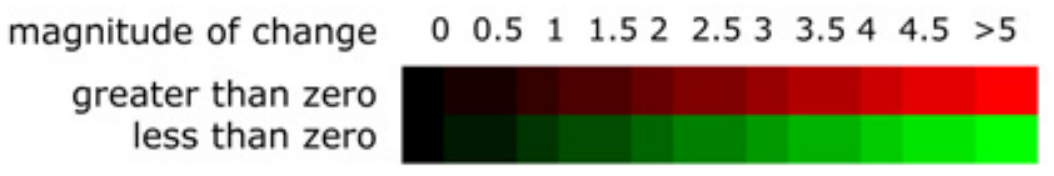

Fig. 1. Expression of A, salicylic acid (SA) B, jasmonic acid (JA), and C, pattern-triggered immunity (PTI) pathway genes in Arabidopsis upon infection with the compatible virus Oilseed rape mosaic virus (ORMV). Whole plants infected with ORMV were harvested at 7 , 14 , and 21 days postinoculation. Total RNA was isolated and used for microarray analysis as previously described (Hu et al. 2011). The heat maps shown here focus on the $\log _{2}$ expression levels of genes involved in defense response via SA, JA, or PTI. 
viruses in systemic-infected Arabidopsis leaf tissue compared with mock-treated tissue (Fig. 2A). To define the potential involvement of PEP signaling in antiviral defenses more closely, we also analyzed the expression of both PEPRI and $P E P R 2$. Infection with TMV, which causes only mild symptoms in Arabidopsis, significantly induced PEPR1 and PEPR2 at 21 days postinoculation (dpi), while the slight enhancement observed for TCV and ORMV infections was statistically not significant (Fig. 2B and C). Overall, these results indicate that components of the danger signaling pathway can be induced by RNA virus infections.

To investigate a potential role of AtPEP signaling in antiviral defenses, we infected WT, the peprl/2 double mutant, as well as mutants of BAK1, a common regulator of PTI responses and interactor of PEPR1/2 upon ligand binding, with TCV sap (Supplementary Fig. S4A). We chose two different BAK1 mutants, namely, the knockout mutant bakl-4 (Chinchilla et al. 2007; Heese et al. 2007) and the single amino-acid mutant bak1-5 (Chinchilla et al. 2007; Heese et al. 2007; Schwessinger et al. 2011), which is impaired in PTI signaling but functions normally in BR signaling. We also included the flg22-specific MAMP receptor mutant $f l s 2$ as a negative control, since an involvement of FLS2 in antiviral defenses seems unlikely (Gomez-Gomez and Boller 2000). At 21 dpi, TCV infection causes growth retardation and altered leaf morphology with rounder and slightly crinkled leaves in Col-0 WT, while the petiole length remains largely unaltered (Fig. 3A). TCV infection of pepr $1 / 2$ and $f l s 2$ mutants produced similar symptoms as observed in the Col-0 WT control plants (Supplementary Fig. S2B). Interestingly, disease symptoms such as growth retardation and altered leaf morphology were strongly enhanced in the bakl-4 and bakl-5 mutants upon TCV infection, suggesting that BAK1-dependent DAMP or MAMP signaling, or both, may be involved in antiviral defense. Consistent with the assumption that disease symptoms would represent a measure for susceptibility, we observed a correlation between disease symptoms and virus accumulation. There was a tendency towards increased accumulation of viral coat protein in bakl mutants (Fig. 3B) and a clearly increased accumulation of viral RNA in bakl mutants, as compared with Col-0 WT, peprl/2, and fls2 (Fig.

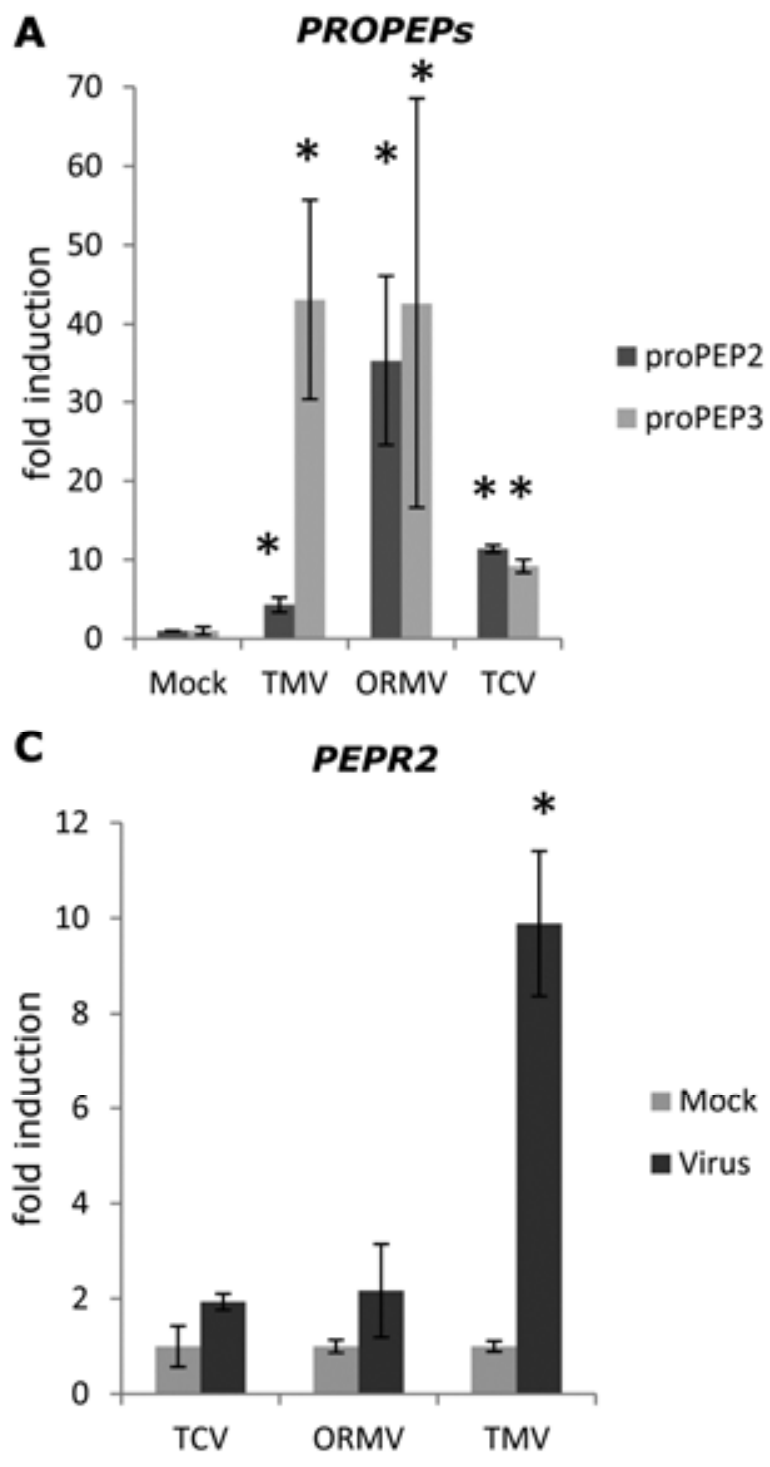

B

PEPR1

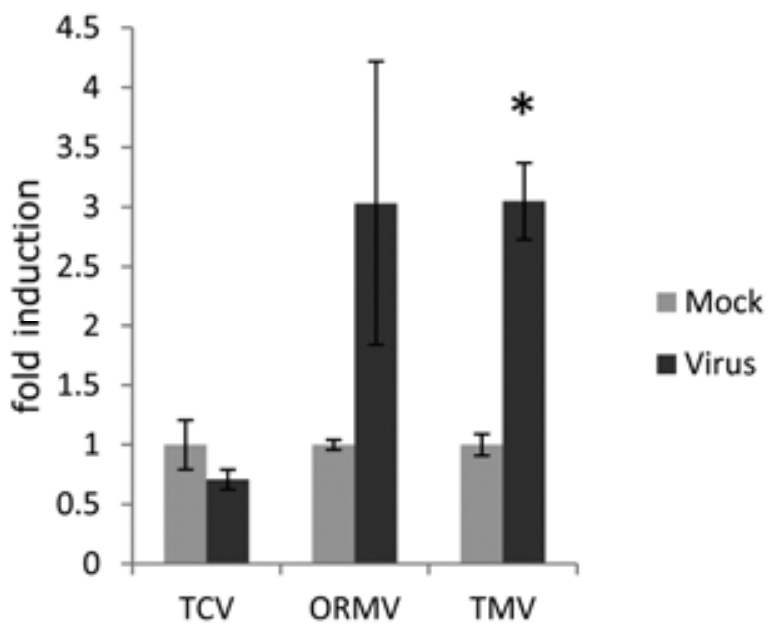

Fig. 2. Components of pattern recognition receptors (PRR)-triggered immunity are upregulated during viral infections. A, PROPEP2 and PROPEP3 are upregulated during infections with the tobamoviriuses Tobaco mosaic virus (TMV) and Oilseed rape mosaic virus (ORMV) as well as the tombusvirus Turnip crinkle virus (TCV). B, PEPR1 is significantly upregulated $(P<0.05$, Student's $t$-test) by TMV but not by ORMV or TCV. $\mathbf{C}, P E P R 2$ is significantly upregulated $(P<0.05$, Student's $t$-test) by TMV but not by ORMV or TCV. Significantly different results $(P<0.05$, Student's $t$-test $)$ are indicated by an asterisk. The error bars represent the standard error of the mean $( \pm)$. All cDNAs were generated from tissue of Arabidopsis Col-0 wild type plants infected with the respective virus for 21 days, and the expression was normalized to the housekeeping gene ubiquitin. These experiments were repeated twice with similar results. 
3C). Together, these results demonstrate that bakl mutants are hypersusceptible to TCV, while peprl/2 or fls 2 mutants exhibit susceptibility to TCV similar to that of WT plants. This suggests that AtPEP signaling is not sufficient to suppress or attenuate viral infection.

To investigate whether the increased susceptibility of bakl mutants was specific for TCV or whether bakl mutants were generally more susceptible to virus infection, we analyzed virusinduced symptoms and virus accumulation of the tobamovirus ORMV, which causes disease in Arabidopsis plants, as indicated by strong viral replication and symptom development. Infection of WT plants with ORMV led to growth retardation, severely curled and serrated leaves with shortened petioles, and compact rosette formation. These symptoms developed similarly in WT as well as in fls 2 and peprl/2 mutants (Supplementary Fig. S3) but were again enhanced in bak1-4 and bak1-5 mutants (Fig. 4A). Enhanced symptom development was paralleled by increased virus accumulation in bakl mutants compared with the WT; we found a tendency towards higher levels of ORMV coat protein (Fig. 4B) and a twofold increase in
ORMV RNA in bakl mutant plants compared with WT and fls 2 and peprl/2 mutants (Fig. 4C). Taken together, the bakl mutants were not only more susceptible for TCV but also for ORMV infection.

Arabidopsis Col-0 plants infected with TCV or ORMV display apparent viral symptoms (Cai et al. 2009; Dempsey et al. 1997). In contrast, TMV infection of Arabidopsis Col-0 plants causes only mild symptoms, including shortened petioles and an overall more compact rosette (Fig. 5A) (Dardick et al. 2000; Pereda et al. 2000; Serrano et al. 2008). Given the strong symptom formation in WT plants upon ORMV and TCV infection, we included the symptomatically weaker TMV to our assays. Similar to the results obtained with ORMV and TCV, TMVassociated symptoms were also enhanced in bakl mutants, characterized by an even more compact rosette than in virus-infected Col-0 plants and altered leaf morphology upon infection (Fig. 5A), while fls 2 and pepr $1 / 2$ mutants displayed similar infection symptoms as the WT control. Consistent with the observation obtained by TCV and ORMV infection that stronger disease symptoms correlate with higher virus titers, the TMV coat pro-
A
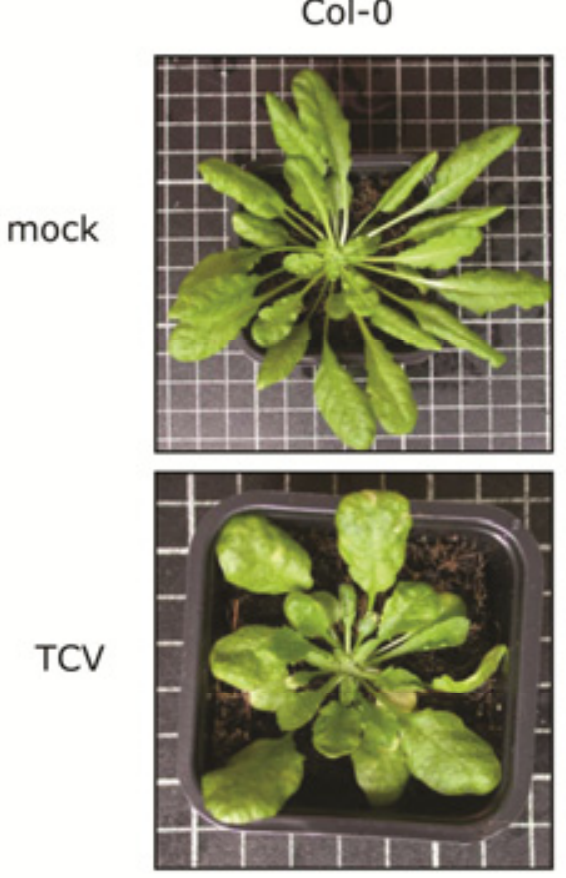

bak1-4
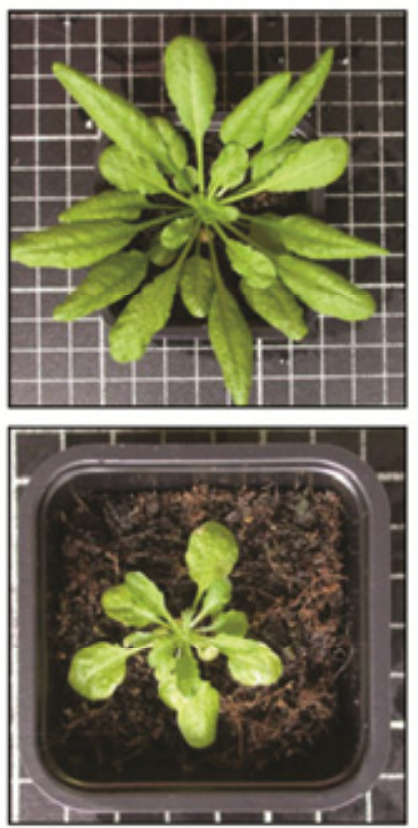

bak1-5
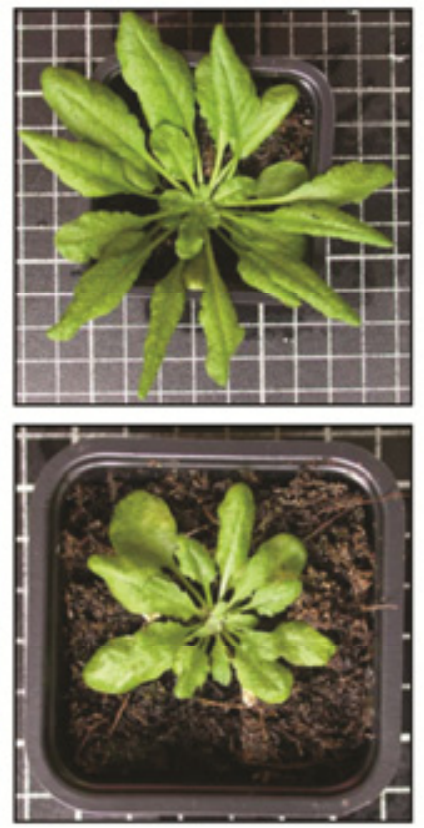

\section{B}

$$
\text { Col-0 pepr bak1-4 bak1-5 fls2 C }
$$

$$
\begin{array}{llllllllll}
\mathrm{m} & \mathrm{T} & \mathrm{m} & \mathrm{T} & \mathrm{m} & \mathrm{T} & \mathrm{m} & \mathrm{T} & \mathrm{m} & \mathrm{T}
\end{array}
$$

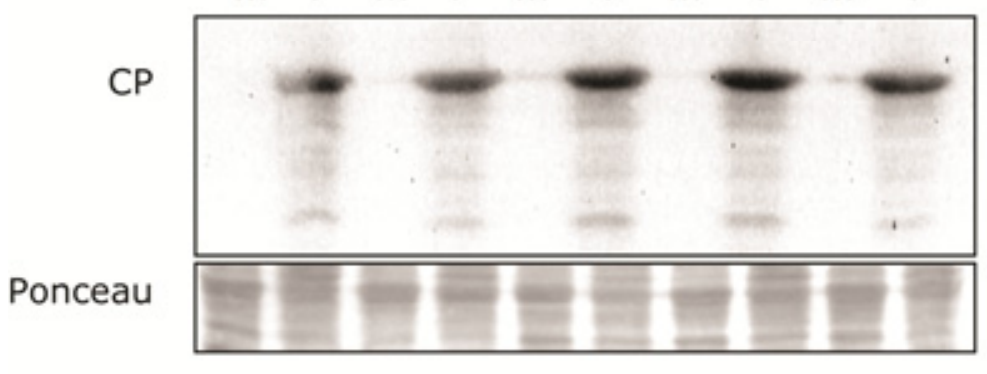

C

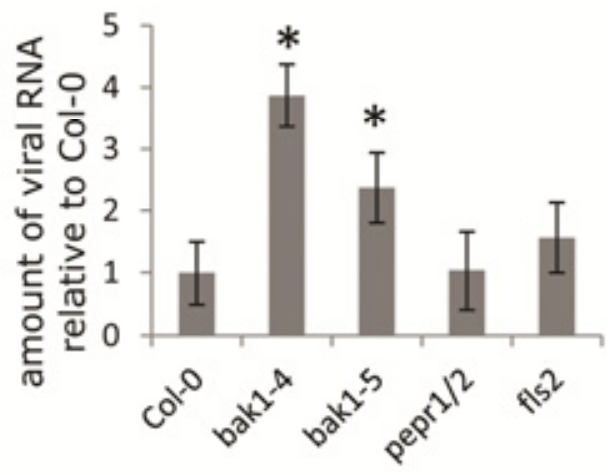

Fig. 3. Characterization of Turnip crinkle virus (TCV) infections at 21 days postinoculation (dpi) in Col-0 wild type (WT) and bakl mutant Arabidopsis lines on symptom and viral accumulation level. A, The average phenotype observed in the different lines. Col-0 WT, the bak1-4 knockout, and the bak1-5 point mutation mutants were infected with TCV crude extract and symptoms were scored 3 weeks postinoculation. B, Expression level of the TCV coat protein (CP) detected by anti-TCV-CP antibodies on Western blots loaded with leaf tissue extracts derived from mock (m) and TCV (T)-infected lines shown in A. C, Quantitative reverse transcription-polymerase chain reaction of TCV CP accumulation in the infected lines shown in A, normalized to the housekeeping gene ubiquitin. The bars represent the mean of three biological repeats with the standard error of the means $( \pm)$ indicated by error bars. Significant results $(P<0.05$, Student's $t$-test $)$ are marked by an asterisk. Each experiment was independently repeated at least twice and the results shown here are representative for each repeat. 
tein appeared slightly more abundant, while the genomic RNA accumulated to significantly higher levels in the bakl mutants compared with WT or $f l s 2$ and pepr $1 / 2$ mutants (Fig. 5B and C).

Taken together, our results suggest that a BAK1-dependent pathway is important in plant defenses against viruses. By contrast, although induction of AtProPEP and PEPR genes suggested that PEP signaling might be involved in antiviral defense, unaffected virus titers and symptoms in pepr $1 / 2$ mutants demonstrate that PEP signaling alone is not sufficient to restrict virus infection in Arabidopsis.

Considering the increased susceptibility of bakl mutants to RNA viruses, we wondered whether extracts of virus-infected leaf tissues contain one or more MAMPs and DAMPs that induce PTI responses in plants. To address this question, we prepared crude extracts of TCV-infected or mock-treated Nicotiana benthamiana leaves and tested whether these extracts were able to induce typical PTI responses, such as MAPK activation, ethylene production, and seedling growth inhibition in Arabidopsis. In plant innate immunity, PRR activation often leads to the downstream phosphorylation of MAPK, which occurs within minutes of MAMP or DAMP treatment (Nühse et al. 2000). To monitor MAPK activation upon crude extract application, we infiltrated highly diluted extracts of mockinfected and TCV-infected $N$. benthamiana plants into Arabidopsis leaves for $15 \mathrm{~min}$. Proteins were extracted and subjected to Western blot analysis, with a commercially available antibody detecting the dually phosphorylated MAPK. Very little activated MAPK was detected when the leaf tissue was treated with $5 \%(\mathrm{vol} / \mathrm{vol})$ mock extract. In contrast, high amounts of activated MAPK were detected when the leaf tissue was treated with $5 \%$ (vol/vol) TCV extract (Fig. 6A).

Besides early responses such as MAPK activation, MAMPs and DAMPs also induce the production of phytohormones. During PTI, the production of ethylene has been particularly well studied and offers a reliable and sensitive method to detect MAMP or DAMP activity (Chinchilla et al. 2006, 2007; Zipfel et al. 2004). Therefore, we also analyzed whether highly diluted TCV extracts were able to induce ethylene production in Arabidopsis. As a negative control, we started by evaluating to what extent the mock extract is capable of inducing ethylene responses in Arabidopsis leaf strips. When the mock extract was applied at $5 \%(\mathrm{vol} / \mathrm{vol})$, we could not observe a significant
A
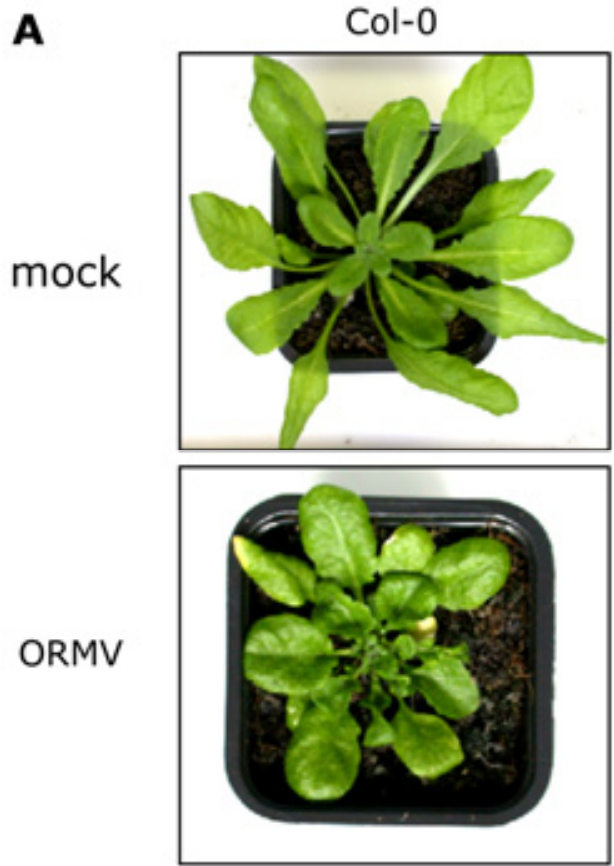

B

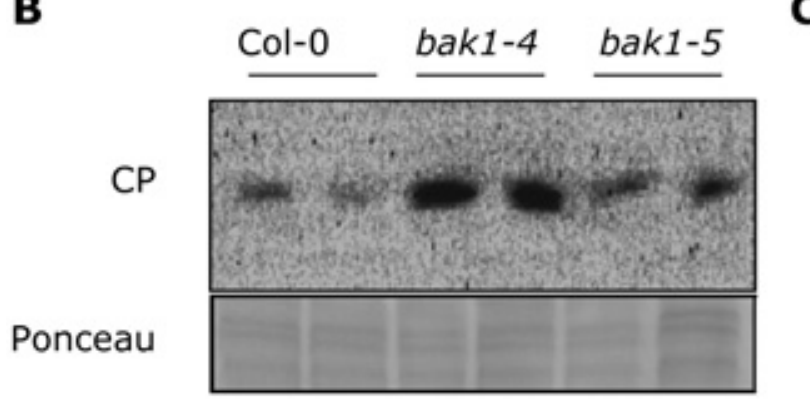

bak1-4
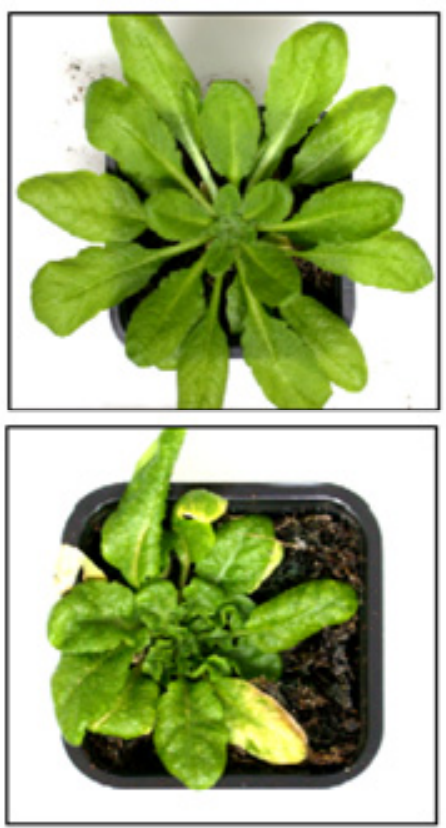

bak1-5
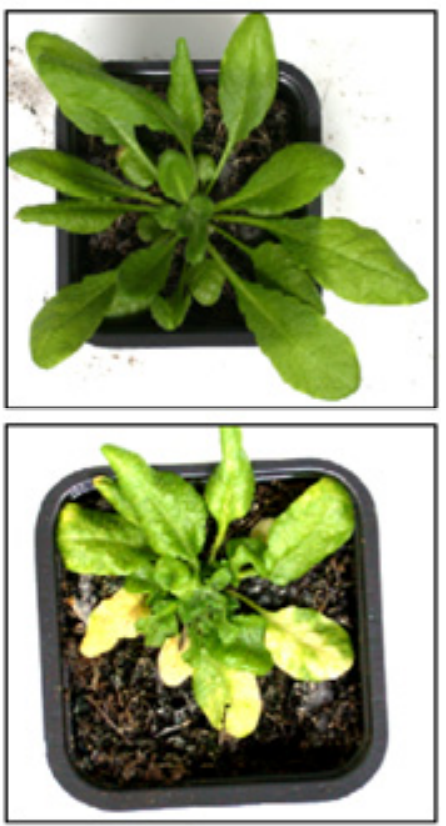

C

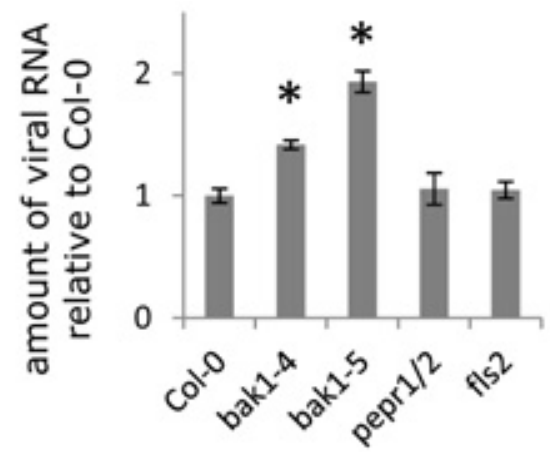

Fig. 4. Characterization of Oilseed rape mosaic virus (ORMV) infections at 21 days postinoculation (dpi) in Col-0 wild type and bak1 mutant Arabidopsis lines on symptom and viral titer level. A, The average phenotype observed in the different lines. Col-0, bak1-4 knockout, and bak1-5 point mutation mutants were infected with ORMV virions and symptoms were scored 3 weeks postinoculation. B, Accumulation of the ORMV coat protein (CP) detected by anti$\mathrm{CP}$ antibodies on Western blots of leaf tissue extracts from the infected lines shown above. The samples were loaded as duplicates. C, Quantitative reverse transcription-polymerase chain reaction of ORMV RNA accumulation in the infected lines shown in A were normalized to the housekeeping gene $u b i q u i t i n$. The bars represent the mean of three biological repeats with the standard error of means $( \pm)$ indicated by error bars. Significant results $(P<0.05$, Student's $t$-test) are marked by an asterisk. Each experiment was independently repeated at least twice and the results shown here are representative for each repeat. 
increase in ethylene, although we repeatedly observed a tendency towards higher ethylene production upon this treatment. However, in contrast to mock extracts, TCV extracts repeatedly induced a significant response (Fig. 6B). The ethylene peak caused by TCV extract was comparable to the response to crude crab-shell chitin, which represents another wellknown MAMP. Compared with flg22, chitin as well as TCV extract induced a much weaker response, although chitin was applied at a high concentration $(100 \mu \mathrm{g} / \mathrm{ml})$. This difference in activity is not surprising, considering that flg22 is a highly purified synthetic peptide applied at very high concentrations $(1 \mu \mathrm{M})$, while the TCV extract represents a complex mixture in which the active compound might only be present in minute amounts. The eliciting molecule may be of proteinaceous nature, as no ethylene response was observed when the crude extracts were pretreated with proteinase $\mathrm{K}$. We compared the ethylene-inducing activity of mock extracts, TCV crude extracts and purified TCV to that of known MAMPs flg22 and chitin. When the mock extract was applied at $5 \%$ (vol/vol), there was no significant increase in ethylene. In contrast, TCV crude ex- tract, applied at the same concentration, caused a marked and significant increase in ethylene production, in a similar range as chitin, albeit to a lesser degree than flg22.

To evaluate the BAK1-dependency of the ethylene response, we also investigated the potential of crude viral extracts to induce ethylene in bakl-4, bakl-5, fls2, and pepr1/2 double mutant plants. The diluted TCV extract induced strong ethylene production in the $f l s 2$ and pepr $1 / 2$ mutants, like that in wild-type plants, but only a small ethylene production in the bak1-4 mutant and none at all in the bak1-5 mutant (Fig. 6B). These results indicate that one or more components of these extracts induces ethylene production in a BAK1-dependent but PEPR1/2-independent manner.

Based on these experiments, it is not clear whether the eliciting activity comes from the plant and, therefore, constitutes a DAMP or is a component of the virus. To address this question, we prepared crude as well as highly purified extracts of TCV-infected or mock-treated control $N$. benthamiana leaves and compared their activities in a third bioassay to examine the activity of elicitors of the PTI response, namely, the seedling
A
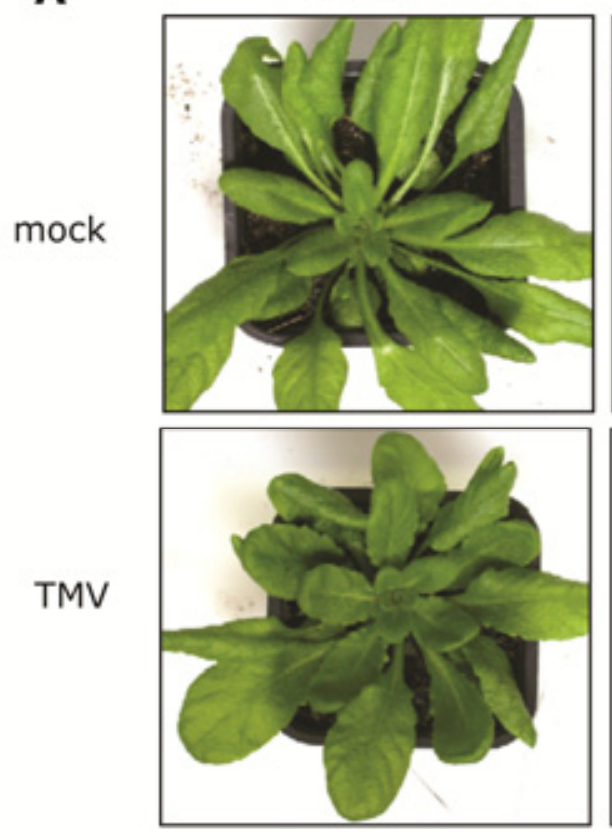

B

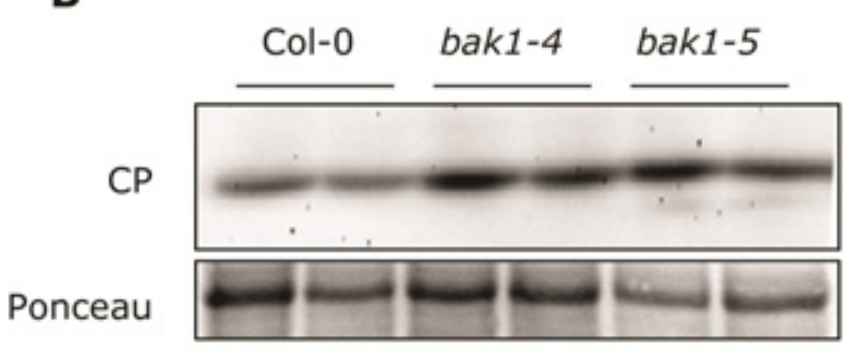

\section{bak1-4}
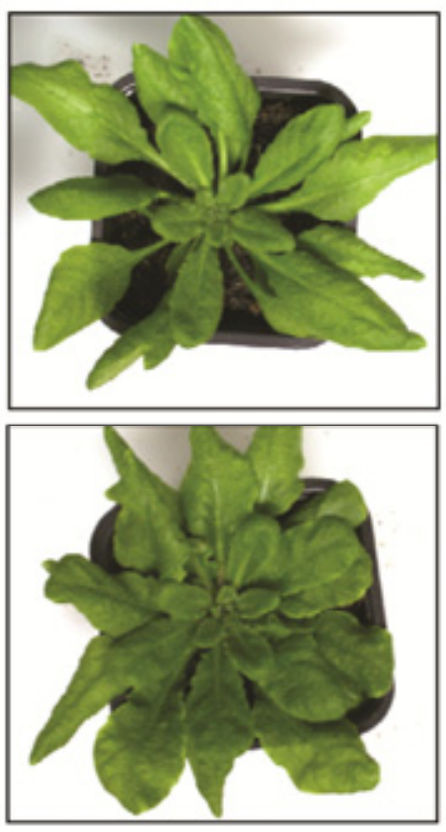

C

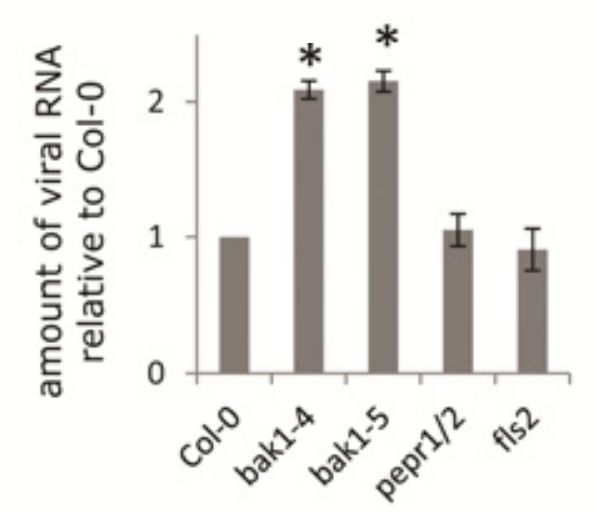

Fig. 5. Characterization of Tobacco mosaic virus (TMV) infections at 21 days postinoculation (dpi) in Col-0 wild type (WT) and bak1 mutant Arabidopsis lines on symptom and viral titer level. A, Average phenotype observed in the different lines. Col-0, bak1-4 knockout, and the bak1-5 point mutation mutants were infected with TMV virions, and symptoms were scored 3 weeks postinoculation. B, Accumulation of the TMV coat protein (CP) detected by anti-CP antibodies on Western blots of leaf-tissue extracts derived from the infected lines shown in A. The samples were loaded as duplicates. C, Quantitative reverse transcription-polymerase chain reaction of TMV RNA accumulation in the infected lines shown in A were normalized to the housekeeping gene ubiquitin. The bars represent the mean of three biological repeats with the standard error of means $( \pm)$ indicated by error bars. Significant results $(P<0.05$, Student's $t$-test) are marked by an asterisk. Each experiment was independently repeated at least twice, and the results shown here are representative for each repeat. 
growth-inhibition assay (Gomez-Gomez et al. 1999; Wang et al. 2010). We applied crude as well as highly purified extracts of TCV-infected $(5 \% \mathrm{vol} / \mathrm{vol})$ or mock-treated control $(5 \%$ $\mathrm{vol} / \mathrm{vol}) N$. benthamiana leaves to one-week-old seedlings of WT, pepr 1/2, fls 2, bak1-4, and bak1-5 and continued to grow these seedlings under continuous light for 10 days. While the overall seedling growth was only slightly affected by crude viral extracts, the roots of WT, fls2, and peprl/2 showed severe growth inhibition (Fig. 6C). Compared with the root-growth inhibition observed by saturating concentrations of flg22, the inhibition was less pronounced but still statistically significant. Whether or not the seedlings became infected by TCV due to long incubations with TCV sap extract has not been investigated. Conversely, the bakl-4 and bakl-5 mutants did not display any significant root-growth inhibition, suggesting that a $B A K 1$-dependent signaling pathway is activated by the crude

A
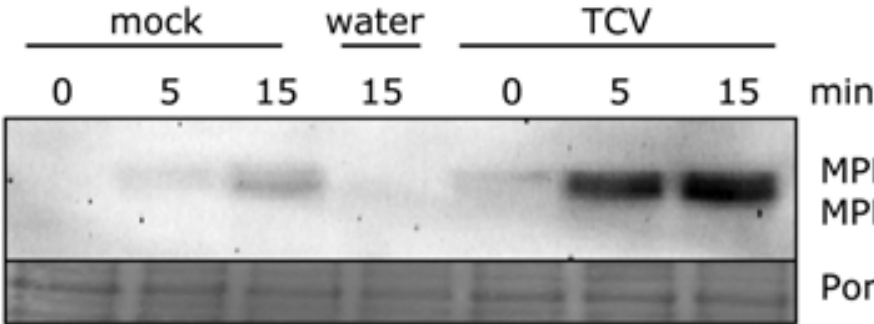

MPK6

MPK3

Ponceau

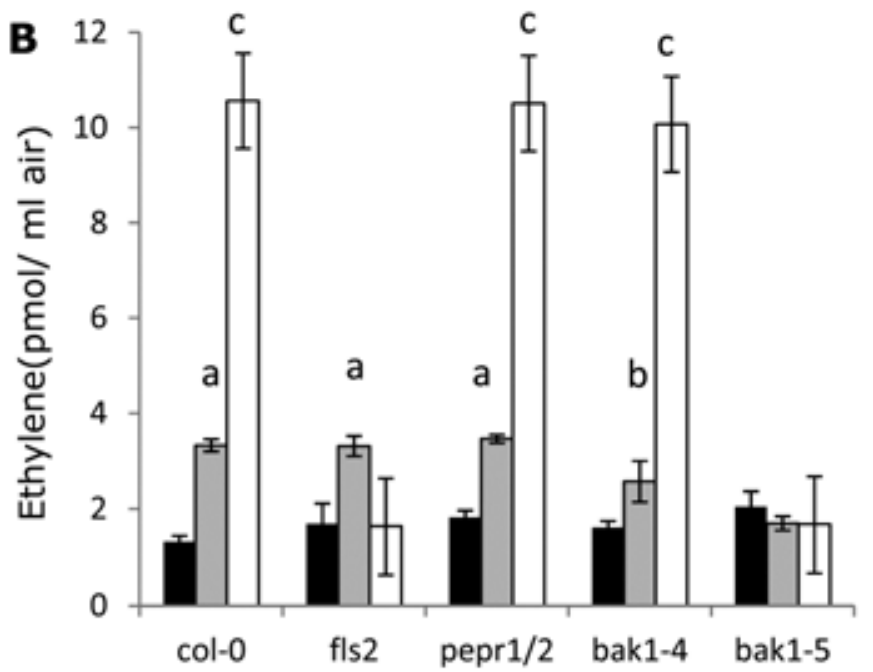

- mock

TCV crude

flg22

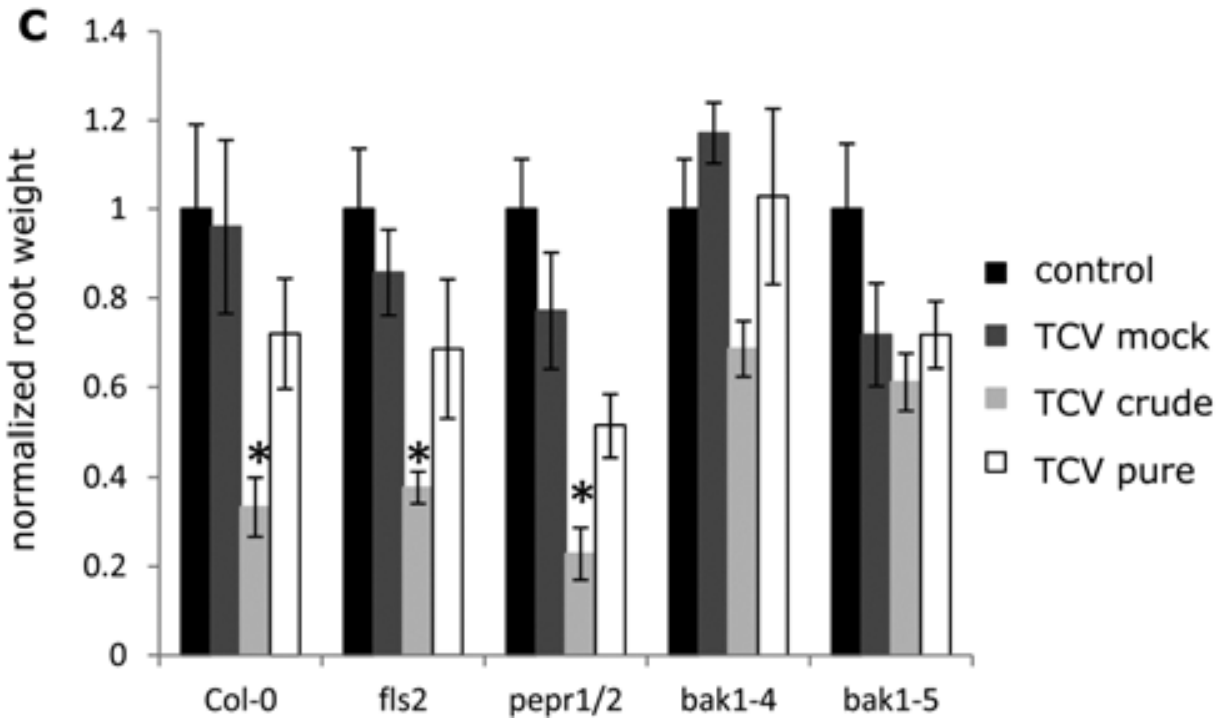

Fig. 6. Compounds within crude extracts of Turnip crinkle virus (TCV)-infected Nicotiana benthamiana leaves induce immune responses in Arabidopsis in a BAK1-dependent manner. A, Four-week-old Arabidopsis leaves $(n=3)$ were infiltrated with crude extracts from mock-infected or TCV-infected $N$. benthamiana leaves. After $15 \mathrm{~min}$, the tissue was harvested, extracted, and subjected to Western blot analysis using anti-pERK1-2 monoclonal antibodies. B, Leaf strips of four-week-old Arabidopsis plants $(n=4)$ of Col-0 wild type (WT), the peprl/pepr 2 double mutant, fls 2 , the bak1-4 knockout, and the bak1-5 point mutation mutants were treated with TCV extract, mock extract, or a positive flg22 control $(1 \mu \mathrm{M})$, and ethylene accumulation was measured $4 \mathrm{~h}$ after treatment. Significant differences $(P<0.05$, one-way analysis of variance) are marked by different letters. C, One-week-old Arabidopsis seedlings of Col-0, the peprl/pepr 2 double mutant, fls2, the bak1-4 knockout, and bak1-5 point mutation mutants $(n=6)$ were treated with crude extracts of TCV-infected leaves or with purified virions in sterile multiplates containing liquid Murashige-Skoog medium, and the root weight was measured 10 days posttreatment $(n=8)$. Significant differences $(P<0.05$, Student $t$-test $)$ are marked by an asterisk. These experiments were repeated at least twice with different sets of extracts and similar results were obtained. 
extract. Interestingly, highly purified extracts of TCV did not induce significant root-growth inhibition (Fig. 6C) or ethylene production. This suggests that the elicitor of root-growth inhibition and, potentially, PTI is not derived from intact TCV virions but is co-extracted from plant tissue or an intermediate product of TCV. Taken together, these results show that one or more compounds in the crude extract from TCV-infected N. benthamiana elicit several PTI responses; this activity is BAK1-dependent and the elicitor perceived is not the virion itself.

\section{DISCUSSION}

Innate immunity constitutes the first line of defense against biotic threats and protects eukaryotes from a wide range of potential pathogens. The perception of MAMPs by PRR activates a range of fast and efficient defense responses that collectively lead to PTI in both animals and plants (Boller and Felix 2009). Plants also sense danger by monitoring cell integrity. If cell integrity is disturbed, plant endogenous DAMPs are either actively or passively released and recognized by PRR at the plasma membrane, leading to PTI-like defense responses (Boller and Felix 2009; Huffaker and Ryan 2007; Krol et al. 2010). Interestingly, compatible virus-host interactions are associated with upregulation of PTI marker genes, indicating that the presence of the viral pathogen is sensed by the host by a yet-unknown mechanism (Love et al. 2005; Whitham et al. 2003).

Here, we present first evidence that viruses are either directly or indirectly recognized by the PTI surveillance system in a BAK1-dependent manner. As a first indication, we observed that mutants in the central PTI regulator $B A K 1$ are more susceptible to three different RNA viruses, namely ORMV, TMV, and TCV. However, BAK1 is not only important for regulation of innate immunity but also involved in cell-death control and brassinosteroid (BR), a phytohormone important for plant growth, signaling (Li et al. 2002; Wang et al. 2008). To exclude the possibility that the increased susceptibility of bakl-4 mutants (knockout mutants) to RNA viruses results from an impairment in BR signaling, we also included the bakl-5 mutant in our analysis (Schwessinger et al. 2011). The bakl-5 mutant is strongly impaired in PTI but not affected in BR responses, in contrast to the bakl-4 mutant, which is impaired in both signaling pathways (Chinchilla et al. 2007; Heese et al. 2007; Li et al. 2002). In all our pathogen assays, the bakl-4 and bak1-5 mutants were similarly affected, suggesting that BR signaling does not contribute to viral replication and symptom development. Interestingly, a viral nuclear shuttle protein of the Tomato yellow spot begomovirus (ToYSV) interacted with the kinase domain of tomato BAK1 in yeast two-hybrid assays, suggesting that it might be an important virulence target for plant viruses (Sakamoto et al. 2012). In addition, this result suggests that BAK1 not only plays an important role in antiviral defense to RNA viruses but also to DNA viruses, because ToYSV is a single-stranded DNA virus. Thus, BAK1 seems to contribute to antiviral defenses due to its role as a central regulator of immunity and independent of its ability to enhance BR signaling. However, since BAK1 appears to be involved in many RLK-mediated pathways, the increased symptom development in bakl mutants could still be indirect and caused by effects on convergent but unrelated pathways. For example, the movement protein (MP) of TMV and ORMV interacts with CDC48 and CDC48 interacts with SERK1, which may activate defense with BAK1 as coreceptor (Aker et al. 2007; Niehl et al. 2012a and b). Thus defenses could be triggered in infected cells through changes at the endoplasmic reticulum (ER) that induce ER stress, i.e., the induction of CDC48 and MP extraction from the ER.
Our results did not reveal differences in susceptibility of peprl/2 mutants to virus infection, although the receptors as well as AtPEP2 and AtPEP3 are upregulated during viral infections. This could be a consequence of functional redundancy among different DAMP perception systems or indicate that the virus-induced PTI response is AtPEP-independent. Still, the involvement of BAK1 in antiviral immunity suggests that either a viral MAMP or a virus-induced DAMP may be recognized by an unknown BAK1-interacting receptor. To test this, we obtained crude and highly purified TCV extracts from infected $N$. benthamiana plants and used them for standard PTI assays in Arabidopsis. Crude but not highly purified TCV extracts induced a number of PTI marker responses, including ethylene production, MAPK activation, and seedling-growth inhibition. Based on these observations, we conclude that TCV-infected tissue contains an elicitor-active compound sufficient for extracellular PTI induction and that intact TCV virions alone are not perceived as a MAMP in Arabidopsis Col-0. This is in line with a previous study that showed TMV coat protein is extracellularly perceived and induces reactive oxygen species production in epidermal peels of tobacco plants shortly after application (Allan et al. 2001). Consistent with the infection assays, ethylene production and seedling-growth inhibition upon crude extract application were BAK1-dependent. The requirement of BAK1 for signaling further suggests that the elicitor is perceived at the plasma membrane. Overall, these results support the hypothesis that PTI responses are induced by PRR-mediated recognition of MAMPs and DAMPs present in the crude extracts.

Since viruses are strictly intracellular, one explanation for the observed PTI induction is that TCV infections lead to the production of a plant-derived DAMP. In support of this hypothesis, only crude extracts resulted in PTI responses while highly purified virions did not. However, the crude TCV extract also contains virus-encoded proteins, viral RNA, or sRNA in their free form. By contrast, purified virion preparations only contain the assembled coat protein and the viral genome packaged inside the particles. Thus, it is equally well possible that viral proteins expressed during infection, viral RNA or viral sRNA, induce PTI responses. However, a conserved recognition mechanism between Arabidopsis and N. benthamiana is likely, since the active compound is recognized in Arabidopsis despite of being obtained from infected tissue of $N$. benthamiana. Overall, we suggest a model in which virus infections continuously release a DAMP and or MAMP into the apoplast, in which the eliciting activity is then recognized by a yet-unknown BAK1dependent receptor. Further research will be needed to identify the antiviral MAMP or DAMP receptor. Our finding that BAK1 is involved in antiviral innate immunity against several RNA viruses makes BAK1 a powerful tool in the search for the virus MAMP or DAMP and its receptor.

\section{MATERIALS AND METHODS}

\section{Plants, growth conditions, and virus inoculation.}

Arabidopsis thaliana plants were grown in growth chambers (Sanyo, Osaka, Japan) at $21^{\circ} \mathrm{C}$ with an 8 -h light and 16 -h dark cycle. To initiate virus infection, two leaves of 4-week-old plants were rub-inoculated either with sap from healthy or TCV-infected plants or with 150 ng purified TMV or ORMV virion particles per leaf.

\section{TCV crude extracts.}

$N$. benthamiana plants were infected with TCV by infiltration of Agrobacterium sp. strain GV3101 carrying pBIN19-TCV or an empty vector construct. At 2 to 3 days postinfiltration, noninfiltrated systemic tissue was harvested and was frozen in 
liquid nitrogen. The tissue was ground and extracted in $1 / 10$ (wt/vol) PBS-Tween $(0.5 \%)$ overnight on a rotation wheel at $4^{\circ} \mathrm{C}$. The extracts were centrifuged three times at $4,000 \times g$ for 15 min to remove cellular debris and were analyzed by sodium dodecyl sulfate-polyacrylamide gel electrophoresis and Coomassie staining. Prior to PTI assays, the extract was diluted 1:20 in distilled water. Extracts were produced at least five times independently and, each time, were analyzed for PTI induction by ethylene measurements. The mock extract derived from empty vector-infiltrated plants was treated exactly the same way as extracts derived from virus-infected plants.

\section{Purified TCV virions.}

Highly purified TCV virions were prepared according to the protocol of Leberman (Songkram et al. 2010).

\section{TMV and ORMV virion preparation.}

TMV- or ORMV-infected leaves were frozen and ground in liquid nitrogen. For each gram of tissue powder, $1 \mathrm{ml}$ of buffer $\mathrm{A}$ $(0.5 \mathrm{M} \mathrm{NaP}, \mathrm{pH} 7,0.1 \% \beta$-mercaptoethanol) and 1 vol of butanol/chloroform (50:50) was added and mixed by shaking (1 to $2 \mathrm{~min}$ ). The mixture was centrifuged for $10 \mathrm{~min}$ at room temperature and $18,111 \times g$. The upper aqueous phase was removed and centrifuged at $20,791 \times g$ for $15 \mathrm{~min}$. Following addition of $1 / 10 \mathrm{vol}$ of $40 \%$ PEG8000 to the upper aqueous phase, incubation for $10 \mathrm{~min}$ on ice, and centrifugation for $10 \mathrm{~min}$ at $18,111 \times g$, supernatant was discarded and the pellet resuspended in 0.2 vol $10 \mathrm{mM} \mathrm{Na} \mathrm{HPO}_{4}, \mathrm{pH}$ 7. The sample was again centrifuged for $10 \mathrm{~min}$ at $5,000 \times g$, and the supernatant was transferred into a fresh $1.5-\mathrm{ml}$ tube. Sodium chloride was added to a total of $1 \%$ and polyethylene glycol to a total of $4 \%$, followed by centrifugation at $5,000 \times g$ for $10 \mathrm{~min}$ and the removal of the supernatant. The final pellet was resuspended in $10 \mathrm{mM} \mathrm{Na} \mathrm{HPO}_{4} \mathrm{pH} 7$ and the concentration measured photometrically, whereby an optical density at $260 \mathrm{~nm}$ value of 3 equals $1 \mathrm{mg}$ of virion particles per milliliter.

\section{Quantitative reverse transcription-polymerase chain reaction (qRT-PCR).}

Arabidopsis total RNA was extracted using the NucleoSpin RNA plant extraction kit (Macherey-Nagel, Düren, Germany) and was treated with rDNase according to the manufacturer's specifications. cDNA was synthesized from $500 \mathrm{ng}$ of RNA with random primers, using the AMV reverse transcriptase system according to the manufacturer's instructions (Promega, Madison, WI, U.S.A.). qRT-PCR was performed in a 96-well format, using a Light Cycler 480 machine (Roche Applied Science, Rotkreuz, Switzerland). On the basis of the obtained cycle threshold values, normalized expression to the reference gene UBQ10 (AT4G05320) was calculated using the qGene protocol (Job et al. 2010). The gene-specific primers used were as follows: $U B Q 10$ (AT4G05320) with UBQ_fw (5'-GGCCT TGTATAATCCCTGATGAATAAG) and UBQ_rv (5'-AAAGA GATAACAGGAACGGAAACATAG), PEPR1 (AT1G73080) with PEPR1_fw (5'-CAACAACAATGTGGAGGATA) and PEPR1_rv (5'-AACGAGATTACCGAACTGAA), PEPR2 (AT1G17750) with PEPR2_fw (5'-AAGAAGATGGCTTAAT GCTG) and PEPR2_rv (5'-GAGTTGTGCCAGTAACAGTG), ProPEP2 (AT5G64890) with ProPEP2_fw (5'-TCACCAAAC TATTGGATTTCAA) and ProPEP2_rv (5'-GACTCAATTGAC TTCTTAATC), ProPEP3 (AT5G64905) with ProPEP3_fw (5'CAACGATGGAGAATCTCAGA) and ProPEP3_rv (5'-CTAA TTGTGTTTGCCTCCTTT), BAK1 (AT4G33430) with BAK1_fw (5'-GACCTTGGGAATGCAAATCTATC) and BAK1_rv (5'-AAAACTGATTGGAGTGAAAAGTGAAA). For the quantification of viral RNA, the following primer combinations were used: TMV with TMV_fw (5'-GACCTGACA
AAAATGGAGAAGATCT) and TMV_rev (5'-GAAAGCGGA CAGAAACCCGCTG), ORMV with ORMV_fw (5'-AGGTG GGGTAACAGTGAGCGTGA) and ORMV_rev (5'-GCTTTC GCTTGGCATCCGCG), TCV with TCV_fw (5'-GTCGATTT CGGCAAACTCAT) and TCV_rev (5'-GCTGGTTGAGCCA GTTCTGT).

\section{MAPK activation assays.}

Arabidopsis leaves of 4- to 6-week-old plants were infiltrated with crude extract from mock-treated or TCV-infected $N$. benthamiana plants ( $5 \% \mathrm{vol} / \mathrm{vol}$ in water) for $15 \mathrm{~min}$. Leaf discs $(50 \mathrm{mg})$ were then frozen in liquid nitrogen and proteins were extracted in $100 \mu \mathrm{l}$ of extraction buffer $(50 \mathrm{mM}$ Tris- $\mathrm{HCl}$, $\mathrm{pH} 7.5,150 \mathrm{nM} \mathrm{NaCl}$, protease inhibitor cocktail [SigmaAldrich, St. Louis]) for $30 \mathrm{~min}$ at $4^{\circ} \mathrm{C}$. Subsequently, $100 \mu \mathrm{l}$ of Lämmli loading buffer $(2 \times)$ were added to each sample. Samples were subjected to immunoblot analysis using the antip42/44-phospho-ERK antibody (Cell Signaling, Rockford, IL U.S.A.). Blots were developed using CDP-star technology (New England Biolabs, Beverly, MA, U.S.A.).

\section{Ethylene production.}

Ethylene production was measured as described previously (Felix et al. 1999). For the induction of ethylene by crude viral extracts, the extracts were added to the water in which the leaf strips were floating at $5 \%(\mathrm{vol} / \mathrm{vol})$.

\section{Seedling growth inhibition assay.}

At 5 days after germination, sterile seedlings were exposed to liquid Murashige-Skoog medium supplied with viral extracts of $5 \%(\mathrm{vol} / \mathrm{vol})$ final concentration or to a control treatment with buffer containing $1 \mu \mathrm{M}$ flg22 (one seedling per 500 $\mu \mathrm{l}$ of medium in 24-well plates). The effect of the treatment on seedling growth was analyzed after 10 days by weighing the fresh dry weight of the roots.

\section{ACKNOWLEDGMENTS}

We would like to thank D. Baulcombe and A. Simon for providing TCV clones and C. Zipfel for the bak1-5 mutant. Funding was gratefully received from the Swiss National Science Foundation (SNF grants 140694 and 144084).

\section{LITERATURE CITED}

Aker, J., Hesselink, R., Engel, R., Karlova, R., Borst, J. W., Visser, A. J., and de Vries, S. C. 2007. In vivo hexamerization and characterization of the Arabidopsis AAA ATPase CDC48A complex using forster resonance energy transfer-fluorescence lifetime imaging microscopy and fluorescence correlation spectroscopy. Plant Physiol. 1452:339-350.

Allan, A. C., Lapidot, M., Culver, J. N., and Fluhr, R. 2001. An early Tobacco mosaic virus-induced oxidative burst in tobacco indicates extracellular perception of the virus coat protein. Plant Physiol. 1261:97108.

Boller, T., and Felix, G. 2009. A renaissance of elicitors: Perception of microbe-associated molecular patterns and danger signals by patternrecognition receptors. Annu. Rev. Plant Biol. 60:379-406.

Cai, L., Chen, K., Zhang, X., Yan, L., Hou, M., and Xu, Z. 2009. Biological and molecular characterization of a crucifer tobamovirus infecting oilseed rape. Biochemical Genetics 47:451-461.

Carr, J. P., Lewsey, M. G., and Palukaitis, P. 2010. Signaling in Induced Resistance. Adv. Virus Res. 76:57-121.

Chinchilla, D., Bauer, Z., Regenass, M., Boller, T., and Felix, G. 2006. The Arabidopsis receptor kinase FLS2 binds flg22 and determines the specificity of flagellin perception. Plant Cell 18:465-476.

Chinchilla, D., Zipfel, C., Robatzek, S., Kemmerling, B., Nurnberger, T., Jones, J. D., Felix, G., and Boller, T. 2007. A flagellin-induced complex of the receptor FLS2 and BAK1 initiates plant defence. Nature 448:497-500.

Chinchilla, D., Shan, L., He, P., de Vries, S., and Kemmerling, B. 2009. One for all: The receptor-associated kinase BAK1. Trends Plant Sci. 14:535-541. 
Dardick, C. D., Golem, S., and Culver, J. N. 2000. Susceptibility and symptom development in Arabidopsis thaliana to Tobacco mosaic virus is influenced by virus cell-to-cell movement. Mol. Plant-Microbe Interact. 13:1139-1144.

Dempsey, D. M. A., Pathirana, M. S., Wobbe, K. K., and Klessig, D. F. 1997. Identification of an Arabidopsis locus required for resistance to Turnip crinkle virus. Plant J. 11:301-311.

Ding, S. W. 2010. RNA-based antiviral immunity. Nat. Rev. Immunol. 10:632-644.

Felix, G., Duran, J. D., Volko, S., and Boller, T. 1999. Plants have a sensitive perception system for the most conserved domain of bacterial flagellin. Plant J. 18:265-276.

Gomez-Gomez, L., and Boller, T. 2000. FLS2: An LRR receptor-like kinase involved in the perception of the bacterial elicitor flagellin in Arabidopsis. Mol. Cell 5:1003-1011.

Gomez-Gomez, L., Felix, G., and Boller, T. 1999. A single locus determines sensitivity to bacterial flagellin in Arabidopsis thaliana. Plant J. $18: 277-284$

Hanssen, I. M., van Esse, H. P., Ballester, A. R., Hogewoning, S.W., Parra, N. O., Paeleman, A., Lievens, B., Bovy, A. G., and Thomma, B. P. 2011. Differential tomato transcriptomic responses induced by Pepino mosaic virus isolates with differential aggressiveness. Plant Physiol. 156:301-318.

Heese, A., Hann, D. R., Gimenez-Ibanez, S., Jones, A. M., He, K., Li, J., Schroeder, J.I., Peck, S. C., and Rathjen, J. P. 2007. The receptor-like kinase SERK3/BAK1 is a central regulator of innate immunity in plants. Proc. Natl. Acad. Sci. U.S.A. 104:12217-12222.

Hu, Q., Hollunder, J., Niehl, A., Korner, C. J., Gereige, D., Windels, D. Arnold, A., Kuiper, M., Vazquez, F., Pooggin, M., and Heinlein, M. 2011. Specific impact of tobamovirus infection on the Arabidopsis small RNA profile. PLoS One 6:e19549. Published online.

Huffaker, A., and Ryan, C. A. 2007. Endogenous peptide defense signals in Arabidopsis differentially amplify signaling for the innate immune response. Proc. Natl. Acad. Sci. U.S.A. 104:10732-10736.

Janeway, C. A., Jr., and Medzhitov, R. 2002. Innate immune recognition. Annu. Rev. Immunol. 20:197-216.

Jensen, S., and Thomsen, A.R. 2012. Sensing of RNA viruses: A review of innate immune receptors involved in recognizing RNA virus invasion. J. Virol. 86:2900-2910.

Job, A., Wakamiya, A., Kehr, G., Erker, G., and Yamaguchi, S. 2010. Electronic tuning of thiazolyl-capped pi-conjugated compounds via a coordination/cyclization protocol with $\mathrm{B}(\mathrm{C} 6 \mathrm{~F} 5)(3)$. Org. Lett. 12:54705473.

Krol, E., Mentzel, T., Chinchilla, D., Boller, T., Felix, G., Kemmerling, B., Postel, S., Arents, M., Jeworutzki, E., Al-Rasheid, K. A., Becker, D., and Hedrich, R. 2010. Perception of the Arabidopsis danger signal peptide 1 involves the pattern recognition receptor AtPEPR 1 and its close homologue AtPEPR2. J. Biol. Chem. 285:13471-13479.

Li, J., Wen, J. Q., Lease, K. A., Doke, J. T., Tax, F. E., and Walker, J. C. 2002. BAK1, an Arabidopsis LRR receptor-like protein kinase, interacts with BRI1 and modulates brassinosteroid signaling. Cell 110:213-222.

Love, A. J., Yun, B. W., Laval, V., Loake, G. J., and Milner, J. J. 2005. Cauliflower mosaic virus, a compatible pathogen of Arabidopsis, engages three distinct defense-signaling pathways and activates rapid systemic generation of reactive oxygen species. Plant Physiol. 139:935-948.

Niehl, A., Amari, K., Gereige, D., Brandner, K., Mely, Y., and Heinlein, M 2012a. Control of Tobacco mosaic virus movement protein fate by CELL-DIVISION-CYCLE protein48. Plant Physiol. 160:2093-2108.

Niehl, A., Amari, K., and Heinlein, M. 2012b. CDC48 function during TMV infection: Regulation of virus movement and replication by deg- radation? Plant Signal Behav. 8(2). Published online.

Nühse, T. S., Peck, S. C., Hirt, H., and Boller, T. 2000. Microbial elicitors induce activation and dual phosphorylation of the Arabidopsis thaliana MAPK 6. J. Biol. Chem. 275:7521-7526.

Pereda, S., Ehrenfeld, N., Medina, C., Delgado, J., and Arce-Johnson, P. 2000. Comparative analysis of TMV-Cg and TMV-U1 detection methods in infected Arabidopsis thaliana. J. Virol. Methods 90:135-142.

Rathinam, V. A., and Fitzgerald, K. A. 2011. Cytosolic surveillance and antiviral immunity. Curr. Opin. Virol. 1:455-462.

Ruiz-Ferrer, V., and Voinnet, O. 2009. Roles of plant small RNAs in biotic stress responses. Annu. Rev. Plant Biol. 60:485-510.

Sakamoto, T., Deguchi, M., Brustolini, O. J., Santos, A. A., Silva, F. F., and Fontes, E. P. 2012. The tomato RLK superfamily: Phylogeny and functional predictions about the role of the LRRII-RLK subfamily in antiviral defense. BMC Plant Biol 12:229.

Schulze, B., Mentzel, T., Jehle, A. K., Mueller, K., Beeler, S., Boller, T., Felix, G., and Chinchilla, D. 2010. Rapid heteromerization and phosphorylation of ligand-activated plant transmembrane receptors and their associated kinase BAK1. J. Biol. Chem. 285:9444-9451.

Schwessinger, B., Roux, M., Kadota, Y., Ntoukakis, V., Sklenar, J., Jones, A., and Zipfel, C. 2011. Phosphorylation-dependent differential regulation of plant growth, cell death, and innate immunity by the regulatory receptor-like kinase BAK1. PLoS Genet. 7:e1002046. Published online.

Serrano, C., Gonzalez-Cruz, J., Jauregui, F., Medina, C., Mancilla, P., Matus, J., and Arce-Johnson, P. 2008. Genetic and histological studies on the delayed systemic movement of Tobacco mosaic virus in Arabidopsis thaliana. BMC Genet. 9:59.

Song, D. H., nd Lee, J. O. 2012. Sensing of microbial molecular patterns by Toll-like receptors. Immunol. Rev. 250:216-229.

Songkram, C., Ohta, K., Yamaguchi, K., Pichierri, F., and Endo, Y. 2010. Conformational control of benzyl-o-carboranylbenzene derivatives and molecular encapsulation of acetone in the dynamically formed space of 1,3,5-tris(2-benzyl-o-carboran-1-yl)benzene. Inorg. Chem. 49:1117411183.

Wang, B., Komurasaki, K., Yamaguchi, T., Shimamura, K., and Arakawa, Y. 2010. Energy conversion in a glass-laser-induced blast wave in air. J. Appl. Phys. 108(12). Published online.

Wang, X., Kota, U., He, K., Blackburn, K., Li, J., Goshe, M. B., Huber, S. C., and Clouse, S. D. 2008. Sequential transphosphorylation of the BRI1/BAK1 receptor kinase complex impacts early events in brassinosteroid signaling. Dev. Cell 15:220-235.

Wasternack, C., Stenzel, I., Hause, B., Hause, G., Kutter, C., Maucher, H. Neumerkel, J., Feussner, I., and Miersch, O. 2006. The wound response in tomato-Role of jasmonic acid. J. Plant Physiol. 163:297-306.

Whitham, S. A., Quan, S., Chang, H. S., Cooper, B., Estes, B., Zhu, T., Wang, X., and Hou, Y. M. 2003. Diverse RNA viruses elicit the expression of common sets of genes in susceptible Arabidopsis thaliana plants. Plant J. 33:271-283.

Yamaguchi, Y., and Huffaker, A. 2011. Endogenous peptide elicitors in higher plants. Curr. Opin. Plant Biol. 14:351-357.

Zipfel, C., and Felix, G. 2005. Plants and animals: A different taste for microbes? Curr. Opin. Plant Biol. 8:353-360.

Zipfel, C., Robatzek, S., Navarro, L., Oakeley, E. J., Jones, J. D., Felix, G., and Boller, T. 2004. Bacterial disease resistance in Arabidopsis through flagellin perception. Nature 428:764-767.

\section{AUTHOR-RECOMMENDED INTERNET RESOURCE}

Genevestigator search engine: www.genevestigator.com/gv 